\title{
Posterior fusion of the subaxial cervical spine: indications and techniques
}

\author{
James K. LiU, M.D., AND Kaushik Das, M.D. \\ Department of Neurosurgery, Saint Vincent's Hospital, New York Medical College, Valhalla and New \\ York, New York
}

\begin{abstract}
The biomechanical stability of the subaxial cervical spine (C3-7) can be compromised by numerous pathological processes, and the restoration of stability may ultimately require fusion and placement of rigid internal fixation devices. A posterior fusion and stabilization procedure is often used to treat cervical instability secondary to traumatic injury, rheumatoid arthritis, ankylosing spondylitis, neoplastic disease, infections, and previous laminectomy. Numerous techniques and advances in spinal instrumentation have evolved over the last 30 years. The authors review the indications and the various methods for stabilizing and fusing the subaxial cervical spine via posterior approaches.
\end{abstract}

KEY WORDS - cervical fusion - spinal fixation • operative technique

The management of patients with spinal disease requires thoughtful and individualized approaches. First, the surgeon must determine whether spinal instability is present. Various definitions and models of determining cervical instability exist in the literature. ${ }^{23,24,66-68}$ White and Panjabi ${ }^{68}$ have defined spinal instability as the loss of the spine's ability to tolerate pain, structural deformity, or neurological damage under physiological loads. Denis ${ }^{23}$ has defined instability as injury to two or more columns in his three-column classification scheme in acute spinal trauma. White and colleagues ${ }^{66}$ have developed a point system based on radiographic and clinical parameters to quantify cervical instability. Although these models aid in operative decision making, each has its limitations and cannot be applied to all clinical scenarios. In practice, however, the presence of instability is suggested by radiographic studies including plain radiographs, computerized tomography, magnetic resonance imaging, and sometimes flexion-extension radiographs. ${ }^{59}$

If cervical instability is present, the surgeon must decide whether conservative management or operative fixation preceded by neural decompression is the best treatment. Once the decision is made to undertake surgical stabilization, the approach and method of spinal fixation are carefully selected. The goal of any fixation device is to provide structural stability until a solid bone fusion has formed. ${ }^{29,30,56}$ Posterior cervical constructs provide stability by restoring the posterior tension band's ability to resist flexion forces. More rigid fixation devices, such as lateral mass plates, provide additional stability in extension, lateral bending, axial rotation, and axial loading. ${ }^{14} \mathrm{Se}$ lecting the optimal posterior fixation hardware requires a thorough knowledge of biomechanics and operative techniques in spinal reconstruction and stabilization. The choice of cervical construct is determined by the nature and extent of the instability as well as the surgeon's familiarity and preference. ${ }^{59}$

\section{HISTORICAL REVIEW}

The earliest description of posterior cervical fusion procedures was the application of autogenous bone grafts to the posterior elements; however, these constructs provided only minimal inherent stability and prevented immediate mobilization. Thus, the patient required long periods of bed rest and an external orthosis to maintain alignment for solid bone fusion to develop. In 1891, Hadra ${ }^{34}$ first described the use of wire to fixate the spine to treat instability secondary to Pott disease and traumatic fractures. Since then, numerous modifications of wiring techniques have developed to secure the spinous processes, laminae, and facets of the cervical spine. ${ }^{15,16,18,19,48,53,55}$ Because of successful results, some of these techniques continue to be viable in the treatment of cervical instability.

In the last several decades, lateral mass plates and screws and interlaminar clamps have been added to the armamentarium for the surgical stabilization if the posterior cervical spine. $8,10,21,25,52$ The intrinsic strength and loadsharing properties of these constructs achieve immediate stabilization while allowing bone fusion to develop. These instrumentation systems allow for early patient mobilization and rehabilitation and may even obviate the need for external orthoses, especially in noncompliant patients. 
TABLE 1

Indications for posterior cervical fusion

Cause of Cervical Instability

trauma

fractures of laminae, pedicles, facets

articular facet dislocation (unilat \& bilat)

posterior ligamentous incompetence

nontraumatic

degenerative cervical instability

spondylosis

articular facet arthropathy

intervertebral disc degeneration

iatrogenic cervical instability

postlaminectomy kyphosis

inflammatory instability

rheumatoid arthritis

ankylosing spondylitis

infectious instability

osteomyelitis (bacterial, fungal, tuberculous) neoplasia

More recently, lateral mass screws and malleable rods have been successfully used to achieve arthrodesis in cases of severe degenerative spondylosis. ${ }^{39}$ Unlike traditional lateral mass plate systems, because screw placement is not dictated by a plate in which there is a predetermined hole, this fixation hardware can be fitted to accommodate spines with severe anatomical deformities. The novel application of pedicle screws to the cervical spine has also been used for fixation of nontrauma- and trauma-induced lesions. ${ }^{1-3,6}$ The biomechanical advantages of the cervical pedicle screw system include threedimensional correction of kyphotic and translational deformity and restoration of disc height and lordotic alignment; 5,6 however, the surgery-related risk of vascular and neural injury when applying this system is still in question. ${ }^{4}$

\section{OPERATIVE INDICATIONS}

The primary goals in spinal stabilization are the following: 1) restoring stability in a biomechanically compromised spine; 2) maintaining alignment to allow development of solid bone fusion; 3 ) preventing progression of a deformity; and 4) alleviating pain. ${ }^{67}$ The causes of instability in the subaxial cervical spine can be classified as traumatic and nontraumatic (Table 1). ${ }^{59}$

\section{Trauma-Induced Injury}

The most frequent indication for posterior stabilization of the subaxial cervical spine is instability secondary to traumatic injury. ${ }^{20,22}$ Initial management consists of spinal realignment, neural element decompressive surgery, and stabilization. If the injury is mainly osseous, neurological compromise is absent, and alignment is reasonable, nonoperative management is effective ${ }^{59,61}$ If , however, there exists ligamentous instability, surgical internal fixation is more efficacious. ${ }^{17,61}$ Using a posterior approach, the surgeon can effectively address instability due to posterior element fractures, facet dislocations, and posterior ligamentous injury. Posterior stabilization may also supple- ment anterior constructs in cases of severe instability or when excessive load on the anterior construct is anticipated. In cases of severe three-column instability, the circumferential, or anterior-posterior procedure is used to restore stability in almost all motion planes. ${ }^{47,60}$ This technique provides immediate rigid stabilization of the cervical spine, obviates the need for halo vest immobilization, and may achieve a higher rate of fusion in cases of complex spinal disorders. ${ }^{50}$

\section{Nontrauma-Induced Injury}

Posterior stabilization also effectively addresses nontraumatic causes of subaxial cervical instability, which include neoplasia, degenerative disease, rheumatoid arthritis, ankylosing spondylitis, infectious processes, and postlaminectomy kyphosis. When placing instrumentation to treat an unstable spine destroyed by metastatic cancer, multilevel fixation constructs must incorporate diseasefree bone above and below the involved vertebral level. Patients with cervical spondylotic myelopathy undergoing multiple decompressive laminectomies can benefit from posterior fixation, as it reduces the incidence of postlaminectomy kyphosis; however, if kyphosis is already present, an anterior stabilization procedure would be more beneficial. ${ }^{37}$ Posterior fixation may also be used as a prophylactic measure to safeguard against anticipated instability due to disease progression or iatrogenic destabilizing maneuvers. ${ }^{14,56}$

\section{OPERATIVE TECHNIQUES FOR SUBAXIAL FIXATION}

A summary of techniques and constructs for subaxial fixation is provided in Table 2 .

\section{Noninstrumented Fusion (Onlay)}

Fusion without instrumentaion can be performed in the cervical spine when there is no need for immediate stabilization or when an external orthosis is being worn. To achieve successful bone fusion, proper preparation of the fusion bed and the use of an autograft are essential. All soft tissues and periosteum should be meticulously removed from the segments that are to be fused. The articular cartilages must be removed from the facet joints by using curettes or a high-speed drill. Residual soft tissues may leave a fibrous interface that would lead to bone nonunion. Each segment that is to be fused should then be

TABLE 2

Posterior techniques and hardware for the subaxial cervical fusion

Technique/Instrumentaion

onlay (noninstrumented fusion)

spinous process wiring

facet wiring

Halifax interlaminar clamps

lateral mass screws \& plates

lateral mass screws \& rods

cervical pedicle screws 
segmentally decorticated to expose the cancellous, bleeding bone. A bone graft is placed over the areas to be fused. An autograft is recommended because it allows the best chance of successful arthrodesis. Cancellous bone is porous, becomes rapidly vascularized, and promotes fusion. Cortical bone can provide structural support if there are any gaps in the fusion bed that need to be filled. In cases in which bone stock is not adequate, allograft may be used.

\section{Wiring and Cabling Techniques}

Since first introduced by Hadra, ${ }^{35}$ many modifications have been made to wire-and-cable techniques for posterior subaxial fixation. ${ }^{15,48,53,55,69}$ Posterior fixation in which wiring and a bone graft are used is generally simple to perform and requires that the posterior elements be intact. This procedure effectively restores the posterior tension band to allow resistance of flexion forces; however, pathological hyperextension is still possible. Morever, because immediate internal stabilization cannot be achieved with bone grafting alone, an external orthosis must be used temporarily. Wire constructs can be created with monofilament wire, Drummond buttons, or braided cables. When cables are tightened using a crimping device, care must be taken not to overtighten, lest the cables pull through thin, osteoporotic bone. ${ }^{14}$

Subaxial wiring can be classified into three groups: 1) interspinous; 2) facet; and 3) sublaminar. ${ }^{59}$ Sublaminar wiring, which requires passage of wire through the spinal canal, has largely been abandoned because this technique poses risk of neurological damage, especially in patients with stenotic spinal canals. ${ }^{20,32}$

\section{Interspinous Wiring}

In 1942, Rogers ${ }^{55}$ initially described interspinous wiring for treatment of trauma-induced cervical instability. This method is designed to stabilize a single motion segment by applying wires that pass through drilled-out holes in the spinous process superiorly and then travel beneath the spinous process of the inferior adjacent segmental level (Fig. 1 left). When fixation involves multiple levels, the wiring techique is performed in an interlocking fashion. Autogenous corticocancellous bone is layered over

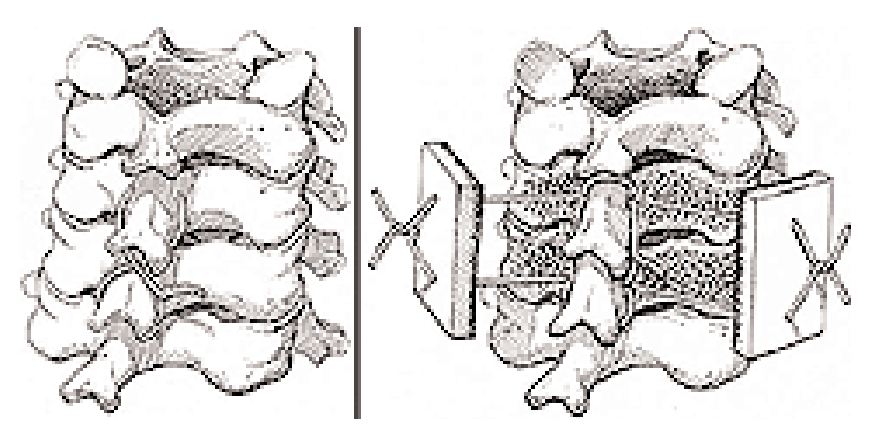

Fig. 1. Spinous process wiring. Left: The Rogers interspinous wiring technique in a figure-eight pattern. Right: Bohlman triplewire technique. After using the Rogers technique, two separate wires are threaded through the holes in upper and lower spinous processes and corticocancellous bone grafts, which are fastened to the decorticated bone to promote fusion. (Reproduced with permission from Barrow Neurological Institute.) the construct to promote arthrodesis. Rogers was able to achieve solid arthrodesis in all 11 patients of his original series. Although various modifications of the technique originated by Rogers have been described by Whitehill, et al., ${ }^{69}$ Benzel and Kesterson, ${ }^{15}$ and Murphy and Southwick, ${ }^{53}$ the fundamental technique remains unchanged.

The Bohlman triple-wire technique is a modification of the Rogers wiring that can be used to stabilize single or multilevel segmental instability. ${ }^{48}$ Initially, interspinous wiring is performed in the same manner as in the Rogers technique. Additional wires are then passed through the holes in the spinous process and threaded through corticocancellous iliac crest bone grafts (Fig. 1 right). The two wires are tightened to secure the bone grafts against the decorticated spinous process and laminae on each side. This technique has been shown to achieve successful arthrodesis in clinical and biomechanical studies. ${ }^{65}$

Facet Wiring. Facet wiring provides a useful alternative in posterior fusion, especially in cases in which the cervical spinous processes and laminae are unavailable as fixation points because of extensive fracture or extensive surgical removal. In 1977, Callahan, et al., ${ }^{19}$ described a technique in which the articular processes are used as fixation points for wiring. This method is effective for stabilizing the spine after extensive laminectomy or when the posterior elements are damaged at multiple levels.

Initially, the entire lateral mass at all levels selected for fusion is exposed. The facet capsular ligaments are removed, and the facet joint is opened. A hole is then drilled perpendicular to the inferior articular process at each level of fixation (Fig. 2). A wire or cable is passed through each hole in a rostral-to-caudal direction and exits through the joint space. The wires are wrapped around autogenous strut grafts and fastened to decorticated articular masses. The caudal end of the bone graft can be secured to the spinous process, thus sparing the caudal facet joint. Alternatively, contoured threaded Steinmann pins or Luque rectangles can be used in place of bone grafts to allow fixation and bone fusion over multiple segments of the cervical spine. ${ }^{31,46}$

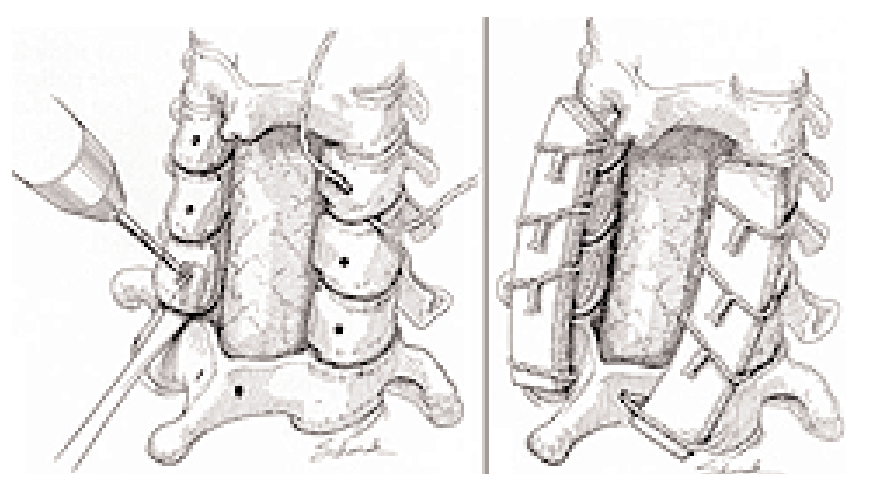

Fig. 2. Callahan facet wiring technique. Left: This technique does not depend on intact laminae or spinous processes. Holes are drilled perpendicular to the inferior articular masses, and a cable is threaded through each articular mass in a rostral-to-caudal direction, exiting through the joint space. Right: Corticocancellous bone grafts are secured to the articular masses by tightening the wires. (Reproduced with permission from Barrow Neurological Institute.) 


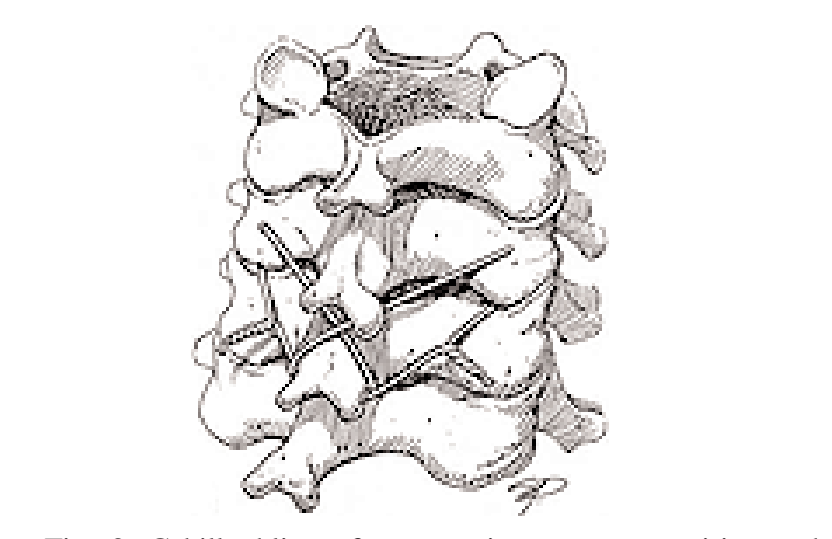

Fig. 3. Cahill oblique facet-to-spinous process wiring technique. A cable is passed through a drilled hole in the midportion of the inferior articular facet and is then looped beneath the spinous process one level below. The same steps are repeated on the contralateral side. (Reproduced with permission from Barrow Neurological Institute.)

For posterior element fractures involving the rostral lamina or spinous process of an unstable motion segment, oblique facet-to-spinous process wiring can be used to stabilize segmental cervical instability. In 1983 Cahill, et. al. ${ }^{18}$ described this technique for the fixation of facet fracture-dislocations or subaxial flexion-compression injuries, and they achieved a $100 \%$ fusion rate in their series of 18 patients. A hole is drilled perpendicular to the midportion of the rostral articular facet. A cable or wire is passed through the hole in the facet and looped beneath the caudal spinous process (Fig. 3). This procedure is repeated on the contralateral side. The lamina and spinous process are decorticated, and bone graft is placed in an onlay fashion.

\section{Interlaminar Clamps}

In 1975, Tucker $^{63}$ reported the first use of Halifax interlaminar clamps for posterior C1-2 arthrodesis. Since then, these devices have been applied to stabilize flexion injuries at a single motion segment at other levels in the subaxial spine. . $, 9,38,62$ Using these clamps in a multilevel fixation is not recommended because of the higher incidence of failure. ${ }^{9}$ These clamps are available in titanium, which is magnetic resonance compatible, and are relatively simple to apply ${ }^{8}$ however, this technique requires intact laminae at the fusion level and may increase the risk of neurological injury by contributing to canal stenosis due to the sublaminar hooks. Most surgeons recommend bilateral placement of interlaminar clamps to optimize fixation and multiplanar stability. ${ }^{9}$

Initially, the posterior elements at the level of fusion are exposed. The leading edge of the lamina above and the trailing edge of the lamina below are thinned bilaterally to augment the interlaminar spaces. The rostral (threaded) clamp is hooked over the leading edge of the upper lamina, and the caudal (unthreaded) clamp is hooked under the trailing edge of the lower lamina (Fig. 4). Screws are applied and the clamps are tightened together. An autologous strut graft can be interposed between the spinous processes to prevent hyperextension and promote fusion. ${ }^{7,59}$

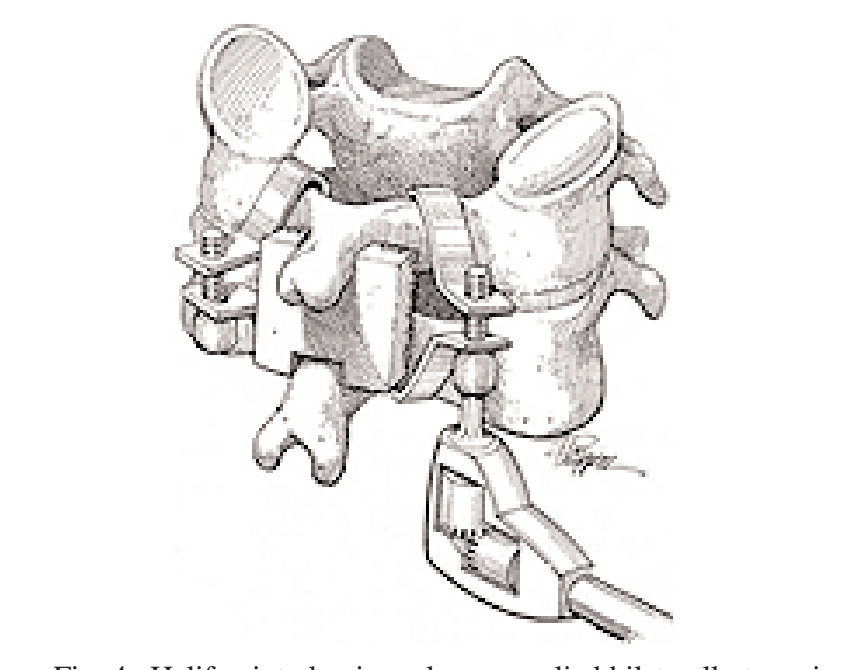

Fig. 4. Halifax interlaminar clamps applied bilaterally to a single level with an interposed bone strut to promote spinal fusion and stability. (Reproduced with permission from Barrow Neurological Institute.)

\section{Lateral Mass Screws and Plates}

Posterior plating systems have emerged as the method of choice in stabilizing the subaxial cervical spine when the posterior elements are absent or compromised. ${ }^{49}$ In the 1980s Roy-Camille and colleagues ${ }^{44,57,58}$ initially introduced the concept of using a lateral mass screw and plate system to stabilize the cervical spine. This technique does not depend on the integrity of the laminae or spinous processes to achieve fixation, and it provides superior rotational stability at the facet joints. Lateral mass plates and screws provide immediate rigid stability, which promotes fusion and obviates the need for external halo vest orthosis. In several biomechanical studies investigators have demonstrated the superiority of posterior cervical fixation over traditional wiring techniques. ${ }^{13,27,33,51,58,64}$ The authors of clinical studies have demonstrated excellent long-term results in the treatment of trauma and degenerative disease. ${ }^{11,13,20,22,28}$

Three major modifications of the original description by Roy-Camille are commonly used in managing cervical instability: 1) Magerl; 2) Anderson; and 3) An. ${ }^{12,13,70}$ Each technique differs in the entrance point for screw insertion and screw trajectory (Fig. 5). The screw is generally directed superiorly and laterally to avoid the nerve root. In one study performed in human cadavers, the investigators found that, of these modifications, the An technique demonstrated the lowest risk of nerve root damage due to overpenetration in drilling or insertion of too long a screw. ${ }^{70}$ In another cadaver study, it was found that if a screw $15 \mathrm{~mm}$ or shorter was used, the chances of injury to the vertebral artery or nerve root were minimized in all three techniques. ${ }^{26,35}$

\section{Lateral Mass Screws and Rods}

In the initial lateral mass plating systems there was a plate with predetermined slots for the placement of screws. Because these plates are restricted in their malleability, they may not accommodate complex spinal abnor- 


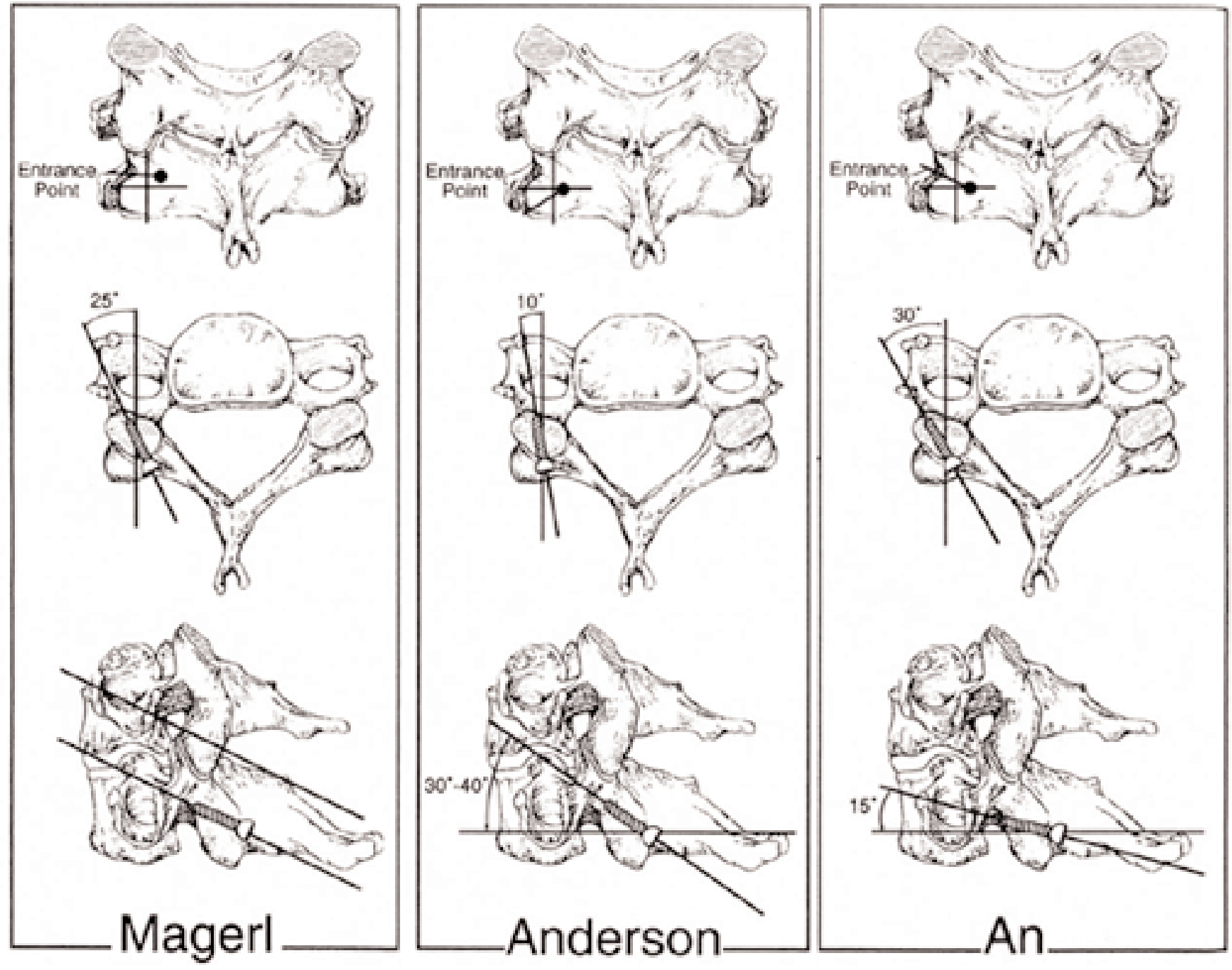

Fig. 5. Left: The Magerl technique. The entrance point for screw insertion is located slightly medial and rostral to the midpoint of the lateral mass. The direction of the screw is $25^{\circ}$ laterally in the axial plane and parallel to the facet joint in the sagittal plane. Center: The Anderson technique. The entrance point for screw insertion is located $1 \mathrm{~mm}$ medial to the midpoint of the lateral mass. The direction of the screw is $10^{\circ}$ lateral in the axial plane and 30 to $40^{\circ}$ rostral in the sagittal plane. Right: The An technique. The entrance point for screw insertion is located $1 \mathrm{~mm}$ medial to the midpoint of the lateral mass. The direction of the screw is $30^{\circ}$ lateral in the axial plane and $15^{\circ}$ rostral in the sagittal plane. (Reprinted with permission from Xu, et al.)

malities. In cases in which the anatomy is distorted, such as in severe degenerative spondylosis or trauma, precise screw placement and realignment is warranted. If the screws do not line up with the plate, a level of screw insertion may need to be skipped. In addition, when the lateral masses are pulled to the plate, there is a risk of iatrogenic foraminal stenosis in the midcervical spine, resulting in radiculopathy. ${ }^{36}$

In an effort to resolve this problem, screw and rod systems have recently been developed and used in preliminary studies. ${ }^{39}$ Currently, there are two systems on the market that use this screw/rod construct: the Cervifix System (Synthes USA) and the Summit System (DepuyAcromed, Inc., Cleveland, OH) (Figs. 6 and 7). These systems allow for placement of the screws into the desired entry point, after which a clamp is placed on the screw.
The Starlock clamp (Synthes USA, Paoli, PA) allows variablility in the medial-to-lateral axis of the screw to facilitate its precise insertion. (Fig. 7 right). Finally, a malleable rod is contoured and threaded through the rod connectors on the clamp, thus completing the construct. The rods are also adaptable to thoracic hooks or pedicle screw constructs (Fig. 7 left). This system accommodates variation in anatomy and thereby allows precise screw placement as well as application of compressive, distractive, or lateral rotatory forces between individual levels of fusion. ${ }^{39}$

There are some disadvantages to this system. Because contouring and threading the rod through the connector can be difficult and time consuming, the lateral mass may be placed at risk of fracturing and instrumentation failure. In current systems there are no polyaxial top-loading screws, but these will soon be commercially available 


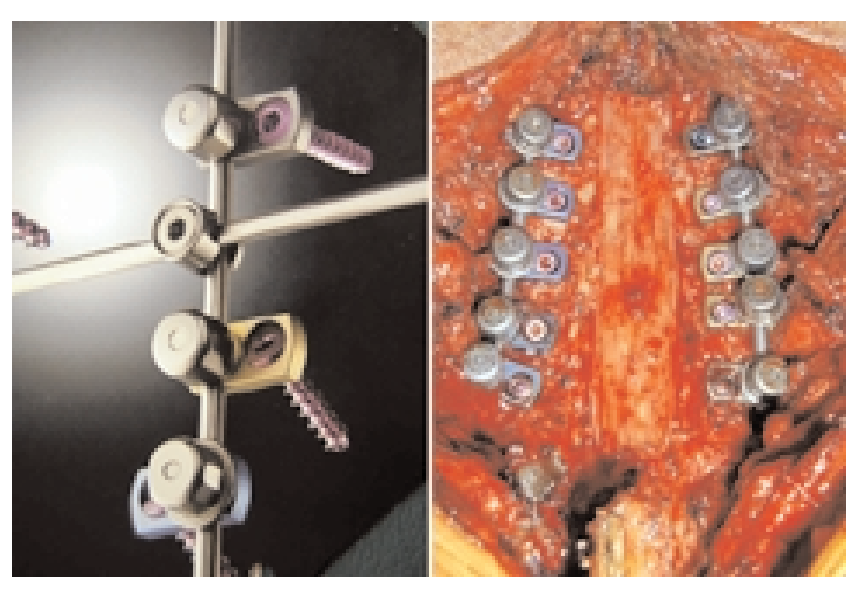

Fig. 6. Left: Summit lateral mass screw and rod system. (Reprinted with permission from Depuy-Acromed Inc.) Right: Intraoperative photograph demonstrating multiple-level fusion after decompressive laminectomy in which the Summit system has been used.

and will significantly reduce the operative time involved in placing the device. Despite initial success with lateral mass screw and rod constructs, the efficacy of this system awaits further confirmation from long-term follow-up studies and biomechanical analysis.

\section{Cervical Pedicle Screws}

Cervical pedicle screws are alternative fixation devices for posterior cervical plating. In 1994 Abumi, et al., ${ }^{1}$ were the first to report the successful use of cervical pedicle screws in managing subaxial traumatic instability. The technique involved in this system provides the most rigid construct with its three-column fixation (Fig. 8A). In biomechanical studies conducted in animal models and human cadavers investigators have demonstrated that this technique offers superior stability, fixation, and resistance to screw pullout forces compared with lateral mass plating. ${ }^{41,43}$ Although experience with this technique is limited ${ }^{40}$ Abumi and colleagues ${ }^{1-3,5,6}$ have demonstrated in clinical studies that cervical pedicle screws can be effectively used in the reconstruction of the cervical spine after decompressive laminectomy, correcting kyphosis from a posterior approach, and reducing trauma-induced disc herniations.

Successful placement of cervical pedicle screws requires a three-dimensional knowledge of the pedicle morphometry to identify accurately ideal screw axis. ${ }^{42,45}$ The anatomy of the cervical pedicle is unfamiliar to most surgeons, and there is significant variability of the entrance and angle of the pedicle. ${ }^{41}$ These anatomical variations raise concern about neurovascular complications that may be encountered in this procedure. In a review of 180 patients, Abumi, et al., ${ }^{4}$ reported one vertebral artery injury, two cases of radiculopathy due to screw insertion, and one case of radiculopathy caused by iatrogenic foraminal stenosis due to excessive reduction. Some authors have advocated computer-assisted image-guidance systems to aid in accurate placement of these screws. ${ }^{45,54}$

Before surgery, preoperative computerized tomography scans should be analyzed carefully to delineate the bone

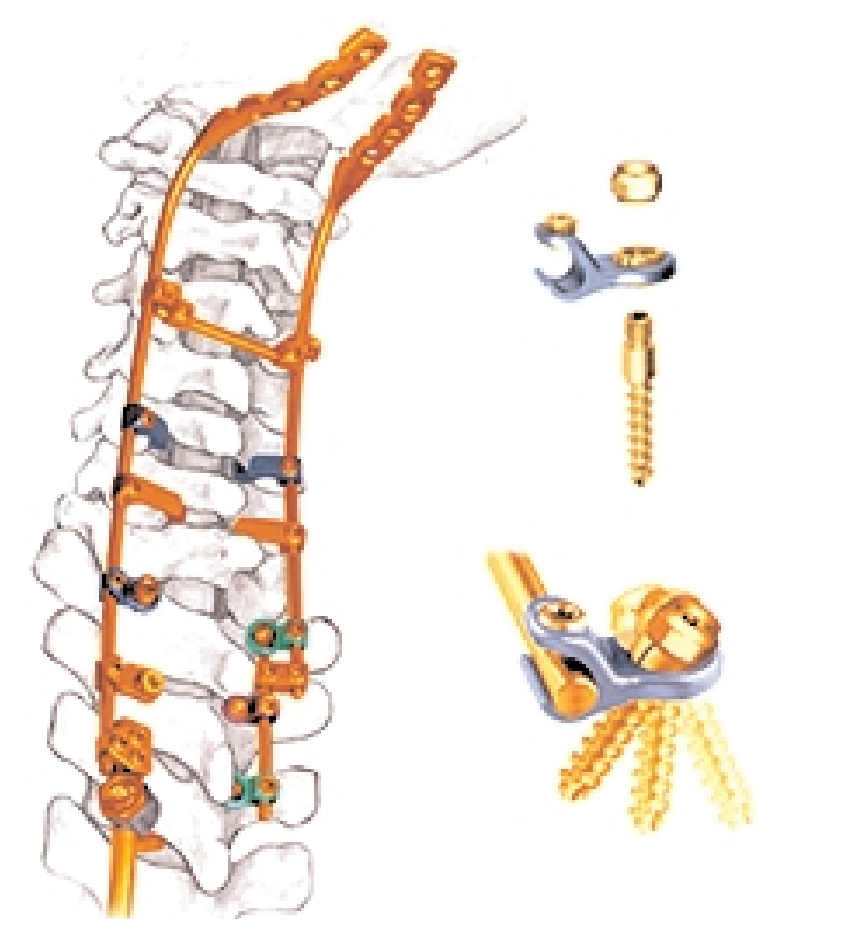

Fig. 7. Left: Titanium Cervifix lateral mass screw and rod system. Its potential application for occipitocervical plating and its adaptability to thoracic instrumentation systems are depicted. Right: The Starlock clamp and screw system. First the screw is placed at desired entry point and trajectory. Then, the clamp (pictured in blue), which incorporates the rod, is attached to the screw and locked with a nut. Rods may be threaded through the connector after clamp placement. The Starlock clamp also allows a variable medial-to-lateral axis of the screw to achieve precise screw insertion. (Reprinted with permission from Synthes USA.)

anatomy and its relation to the vertebral artery and neural structures. Once the posterior elements are exposed to the lateral margin of the articular masses, the point of pedicle screw insertion is penetrated with a high-speed drill. The entry point has been determined to be lateral to the center of the facet and close to the posterior margin of the superior articular surface. ${ }^{1}$ The angle at which the screw is inserted can vary from 25 to $45^{\circ}$ medial to the midline in the transverse plane (Fig. 8B). In the sagittal plane, the angle of insertion should be parallel to the upper endplate for the pedicles of C-5 to C-7, and in a slightly cephalad direction for the pedicles of C-2 to C-4 (Fig. 8C). ${ }^{2}$ After making the entrance hole, a fluoroscopy-guided small pedicle probe is inserted into the pedicle. Thereafter, the appropriate pedicle screw is tapped and inserted. Plates, rods, and bone graft are applied to promote fusion.

\section{CONCLUSIONS}

In summary, posterior-approach fusion of the cervical spine remains an excellent treatment for managing cervical instability. The goal of the techniques described in this paper is to provide the proper environment for the formation of bone fusion. Wiring methods and clamps effectively reconstitute the posterior tension band and can be used alone or to supplement other constructs. Lateral mass 


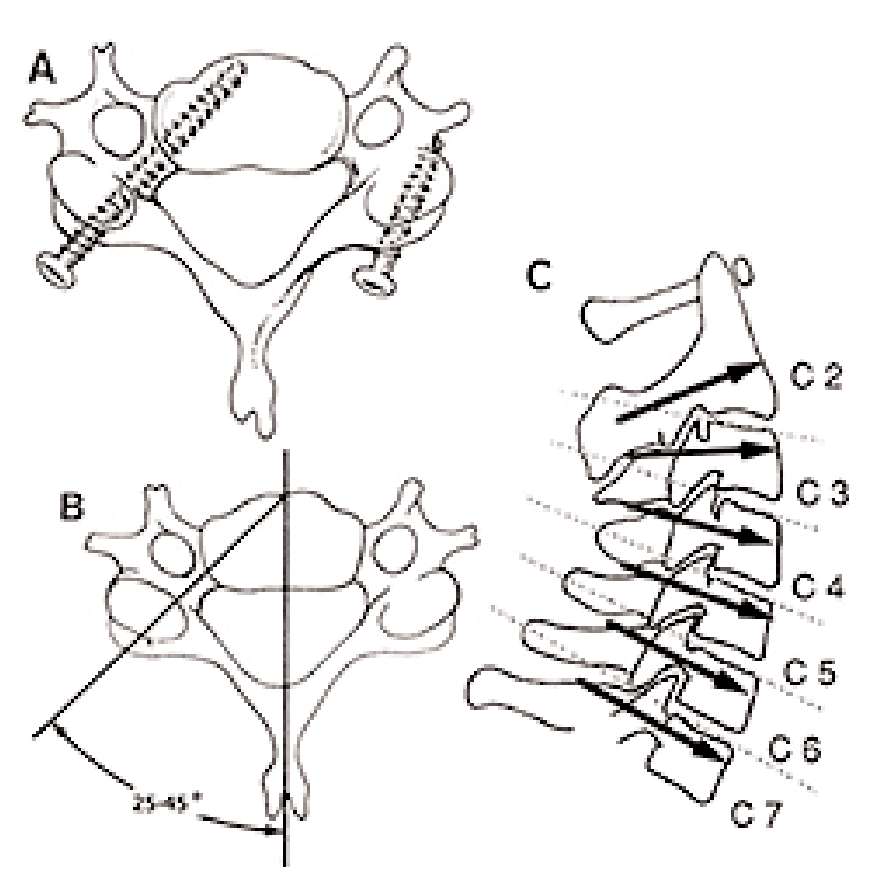

Fig. 8. A: Cervical pedicle screw (left screw) achieves rigid three-column fixation in contrast with lateral mass screw (right screw). B: Placement of cervical pedicle screws requires precision and thorough knowledge of the anatomy to avoid damage to the vertebral artery and neural elements. The angle of the screw insertion can vary from 25 to $45^{\circ}$ medial to the midline in the axial plane (modified with permission from Jones EL, et al.) C: In the sagittal plane, the angle of screw insertion should be parallel to the upper endplates for the pedicles of $\mathrm{C}-5$ to $\mathrm{C}-7$ and in a slightly cephalad direction for the pedicles of C-2 to C-4. (Reprinted with permission from Abumi and Kaneda.)

plates and screws provide additional stability in rotation, lateral bending, and extension. New developments of lateral mass screw/rod constructs accommodate spines with variable anatomy. Cervical pedicle screws, the most rigid construct, provide three-column fixation. All of these devices and the respective techniques performed to place them are valuable tools in the armamentarium of the spinal surgeon. The effectiveness of lateral mass screw/rod systems and cervical pedicle screws awaits further longterm clinical follow-up findings and biomechanical analysis.

\section{References}

1. Abumi K, Itoh H, Taneichi H, et al: Transpedicular screw fixation for traumatic lesions of the middle and lower cervical spine: description of the techniques and preliminary report. J Spinal Disord 7:19-28, 1994

2. Abumi K, Kaneda K: Pedicle screw fixation for nontraumatic lesions of the cervical spine. Spine 22:1853-1863, 1997

3. Abumi K, Kaneda K, Shono Y, et al: One-stage posterior decompression and reconstruction of the cervical spine by using pedicle screw fixation systems. J Neurosurg 90 (Suppl 1): 19-26, 1999

4. Abumi K, Shono Y, Ito M, et al: Complications of pedicle screw fixation in reconstructive surgery of the cervical spine. Spine 25:962-969, 2000

5. Abumi K, Shono Y, Kotani Y, et al: Indirect posterior reduction and fusion of the traumatic herniated disc by using a cervical pedicle screw system. J Neurosurg 92 (Suppl 1):30-37, 2000
6. Abumi K, Shono Y, Taneichi H, et al: Correction of cervical kyphosis using pedicle screw fixation systems. Spine 24: 2389-2396, 1999

7. Aldrich EF: Halifax interlaminar clamps: indications and operative technique. Contemp Neurosurg 15:1-6, 1993

8. Aldrich EF, Crow WN, Weber PB, et al: Use of MR imagingcompatible Halifax interlaminar clamps for posterior cervical fusion. J Neurosurg 74:185-189, 1991

9. Aldrich EF, Weber PB, Crow WN: Halifax interlaminar clamp for posterior cervical fusion: a long-term follow-up review. J Neurosurg 78:702-708, 1993

10. Alexander E Jr: Posterior fusions of the cervical spine. Clin Neurosurg 28:273-296, 1981

11. An HS, Coppes MA: Posterior cervical fixation for fracture and degenerative disc disease. Clin Orthop 335:101-111, 1997

12. An HS, Gordin R, Renner K: Anatomic considerations for plate-screw fixation of the cervical spine. Spine 16 (Suppl 10): S548-S551, 1991

13. Anderson PA, Henley MB, Grady MS, et al: Posterior cervical arthrodesis with AO reconstruction plates and bone graft. Spine 16 (Suppl 3):S72-S79, 1991

14. Baskin JJ, Sawin PD, Dickman CA, et al: Surgical techniques for stabilization of the subaxial cervical spine, in Schmidek HH (ed): Schmidek \& Sweet Operative Neurosurgical Techniques: Indications, Methods, and Results, ed 4. Philadelphia: WB Saunders, 2000, Vol 2, pp 2075-2104

15. Benzel EC, Kesterson L: Posterior cervical interspinous compression wiring and fusion for mid to low cervical spinal injuries. J Neurosurg 70:893-899, 1989

16. Bohlman HH: Acute fractures and dislocations of the cervical spine. An analysis of three hundred hospitalized patients and review of the literature. J Bone Joint Surg Am 61:1119-1142, 1979

17. Bucholz RD, Cheung KC: Halo vest versus spinal fusion for cervical injury: evidence from an outcome study. J Neurosurg 70:884-892, 1989

18. Cahill DW, Bellegarrigue R, Ducker TB: Bilateral facet to spinous process fusion: a new technique for posterior spinal fusion after trauma. Neurosurgery 13:1-4, 1983

19. Callahan RA, Johnson RM, Margolis RN, et al: Cervical facet fusion for control of instability following laminectomy. J Bone Joint Surg Am 59:991-1002, 1977

20. Cooper PR: Stabilization of fractures and subluxations of the lower cervical spine, in Cooper PR (ed): Management of Posttraumatic Spinal Instability. Park Ridge, IL: American Association of Neurological Surgeons, 1990, pp 111-113

21. Cooper PR: Posterior stabilization of the cervical spine. Clin Neurosurg 40:286-320, 1993

22. Cooper PR, Cohen A, Rosiello A, et al: Posterior stabilization of cervical spine fractures and subluxations using plates and screws. Neurosurgery 23:300-306, 1988

23. Denis F: Spinal instability as defined by the three-column spine concept in acute spinal trauma. Clin Orthop 189:65-76, 1984

24. Denis F: The three column spine and its significance in the classification of acute thoracolumbar spinal injuries. Spine 8: 817-831, 1983

25. Domenella G, Berlanda P, Bassi G: Posterior-approach osteosynthesis of the lower cervical spine by the R. Roy-Camille technique. (Indications and first results.) Ital J Orthop Traumatol 8:235-244, 1982

26. Ebraheim NA, Klausner T, Xu R, et al: Safe lateral-mass screw lengths in the Roy-Camille and Magerl techniques. An anatomic study. Spine 23:1739-1742, 1998

27. Errico T, Uhl R, Cooper P, et al: Pullout strength comparison of two methods of orienting screw insertion in the lateral masses of the bovine cervical spine. J Spinal Disord 5:459-463, 1992

28. Fehlings MG, Cooper PR, Errico TJ: Posterior plates in the management of cervical instability: long-term results in 44 patients. J Neurosurg 81:341-349, 1994 
29. Fessler RG: Decision making in spinal instrumentation. Clin Neurosurg 40:227-242, 1993

30. Fielding JW: The status of arthrodesis of the cervical spine. J Bone Joint Surg Am 70:1571-1574, 1988

31. Garfin SR, Moore MR, Marshall LF: A modified technique for cervical facet fusions. Clin Orthop 230:149-153, 1988

32. Geremia GK, Kim KS, Cerullo L, et al: Complications of sublaminar wiring. Surg Neurol 23:629-635, 1985

33. Gill K, Paschal S, Corin J, et al: Posterior plating of the cervical spine. A biomechanical comparison of different posterior fusion techniques. Spine 13:813-816, 1988

34. Hadra BE: Wiring the spinous processes in Pott's disease. Trans Am Orthop Assoc 4:206-210, 1891

35. Heller JG, Carlson GD, Abitbol JJ, et al: Anatomic comparison of the Roy-Camille and Magerl techniques for screw placement in the lower cervical spine. Spine 16 (Suppl 10):S552-S557, 1991

36. Heller JG, Silcox DH, Sutterlin CE III: Complications of posterior cervical plating. Spine 20:2442-2448, 1995

37. Herman JM, Sonntag VKH: Cervical corpectomy and plate fixation for postlaminectomy kyphosis. J Neurosurg 80:963-970, 1994

38. Holness RO, Huestis WS, Howes WJ, et al: Posterior stabilization with an interlaminar clamp in cervical injuries: technical note and review of the long term experience with the method. Neurosurgery 14:318-322, 1984

39. Horgan MA, Kellogg JX, Chesnut RM: Posterior cervical arthrodesis and stabilization: an early report using a novel lateral mass screw and rod technique. Neurosurgery 44:1267-1272, 1999

40. Jeanneret B, Gebhard JS, Magerl F: Transpedicular screw fixation of articular mass fracture-separation: results of an anatomical study and operative technique. J Spinal Disord 7:222-229, 1994

41. Jones EL, Heller JG, Silcox DH, et al: Cervical pedicle screws versus lateral mass screws. Anatomic feasibility and biomechanical comparison. Spine 22:977-982, 1997

42. Karaikovic EE, Kunakornsawat S, Daubs MD, et al: Surgical anatomy of the cervical pedicles: landmarks for posterior cervical pedicle entrance localization. J Spinal Disord 13:63-72, 2000

43. Kotani Y, Cunningham BW, Abumi K, et al: Biomechanical analysis of cervical stabilization systems. An assessment of transpedicular screw fixation in the cervical spine. Spine 19: 2529-2539, 1994

44. Levine AM, Mazel C, Roy-Camille R: Management of fracture separations of the articular mass using posterior cervical plating. Spine 17 (Suppl 10):S447-S454, 1992

45. Ludwig SC, Kramer DL, Vaccaro AR, et al: Transpedicle screw fixation of the cervical spine. Clin Orthop 359:77-88, 1999

46. Maurer PK, Ellenbogen RG, Ecklund J, et al: Cervical spondylotic myelopathy: treatment with posterior decompression and Luque rectangle bone fusion. Neurosurgery 28:680-684, 1991

47. McAfee PC, Bohlman HH: One-stage anterior cervical decompression and posterior stabilization with circumferential arthrodesis. A study of twenty-four patients who had a traumatic or a neoplastic lesion. J Bone Joint Surg Am 71:78-88, 1989

48. McAfee PC, Bohlman HH, Wilson WL: The triple wire fixation technique for stabilization of acute cervical fracture-dislocations: a biomechanical analysis. Orthop Trans 9:142, 1985

49. McCullen GM, Garfin SR: Spine update: cervical spine internal fixation using screw and screw-plate constructs. Spine 25: 643-652, 2000

50. McNamara MJ, Devito DP, Spengler DM: Circumferential fusion for the management of acute cervical spine trauma. J Spinal Disord 4:467-471, 1991

51. Montesano PX, Juach EC, Anderson PA, et al: Biomechanics of cervical spine internal fixation. Spine 16 (Suppl 3):S10-S16, 1991
52. Murphy MJ, Daniaux H, Southwick WO: Posterior cervical fusion with rigid internal fixation. Orthop Clin North Am 17: $55-65,1986$

53. Murphy MJ, Southwick WO: Posterior approaches and fusions, in Cervical Spine Research Society (ed): The Cervical Spine, ed 2. Philadelphia: JB Lippincott, 1989, pp 775-791

54. Nolte LP, Zamorano LJ, Jiang Z, et al: Image-guided insertion of transpedicular screws. A laboratory set-up. Spine 20: 497-500, 1995

55. Rogers WA: Treatment of fracture-dislocation of the cervical spine. J Bone Joint Surg Am 24:245-258, 1942

56. Ronderos JF, Dickman CA, Sonntag VKH: Posterior instrumentation of the cervical spine, in Youmans JR (ed): Neurological Surgery, ed 4. Philadelphia: WB Saunders, 1996, Vol 3, pp 2297-2314

57. Roy-Camille R, Saillant G, Laville C, et al: Treatment of lower cervical spine injuries-C3 to C7. Spine 17 (Suppl 10): S442-S446, 1992

58. Roy-Camille R, Saillant G, Mazel C: Internal fixation of the unstable cervical spine by a posterior osteosynthesis with plates and screws, in Cervical Spine Research Society (ed): The Cervical Spine, ed 2. Philadelphia: JB Lippincott, 1989, pp 390-403

59. Sawin PD, Sonntag VKH: Techniques of posterior subaxial cervical fusion. Oper Tech Neurosurg 1:72-83, 1998

60. Schultz KD, McLaughlin MR, Haid RW Jr, et al: Single-stage anterior-posterior decompression and stabilization for complex cervical spine disorders. J Neurosurg 93 (Suppl 2):214-221, 2000

61. Sonntag VKH, Hadley MN: Nonoperative management of cervical spine injuries. Clin Neurosurg 34:630-649, 1988

62. Statham P, O'Sullivan M, Russell T: The Halifax interlaminar clamp for posterior cervical fusion: initial experience in the United Kingdom. Neurosurgery 32:396-399, 1993

63. Tucker HH: Technical report: method of fixation of subluxed or dislocated cervical spine below C1-C2. Can J Neurol Sci 2: 381-382, 1975

64. Ulrich C, Woersdoerfer O, Kalff R, et al: Biomechanics of fixation systems to the cervical spine. Spine 16 (Suppl 3):S4-S9, 1991

65. Weiland DJ, McAfee PC: Posterior cervical fusion with triplewire strut graft technique: one hundred consecutive patients. J Spinal Disord 4:15-21, 1991

66. White AA, Johnson RM, Panjabi MM, et al: Biomechanical analysis of clinical stability in the cervical spine. Clin Orthop 109:85-96, 1975

67. White AA III, Panjabi MM: Biomechanical considerations in the surgical management of the spine, in White AA III, Panjabi MM (eds): Clinical Biomechanics of the Spine. Philadelphia: JB Lippincott, 1990, pp 511-634

68. White AA III, Panjabi MM: Clinical instability of the spine, in Evarts CM (ed): Surgery of the Musculoskeletal System. New York: Churchill Livingstone, 1983, Vol 2, pp 4:219-4:244

69. Whitehill R, Reger SI, Fox E, et al: The use of methylmethacrylate cement as an instantaneous fusion mass in posterior cervical fusions: a canine in vivo experimental model. Spine 9:246-252, 1984

70. Xu R, Haman SP, Ebraheim NA, et al: The anatomic relation of lateral mass screws to the spinal nerves. A comparison of the Magerl, Anderson, and An techniques. Spine 24:2057-2061, 1999

Manuscript received February 21, 2001.

Accepted in final form March 20, 2001.

Address reprint requests to: Kaushik Das, M.D., Deparment of Neurosurgery, Suite NR 809, Saint Vincent's Hospital, 153 West 11th Street, New York, New York 10011. email: kdas25@ hotmail.com. 